\title{
I wish someone had told me
}

\author{
Developing soft skills can be an important part of a successful academic career. Elisa De Ranieri shares \\ her views on how students can hone theirs.
}

W

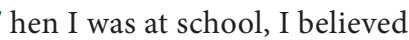
I was being taught an accurate and exhaustive description of the universe - in my mind, knowledge was written in stone. It was only once I was an undergraduate that I fully appreciated that our understanding of the world is a dynamic process: it has evolved since the dawn of civilization and has not yet reached its apex (and, in fact, may never). What we learn from books reflects only our current, limited understanding of affairs. To any researcher, this is obvious, but not so for a young student. Later, as I went through my $\mathrm{PhD}$ and postdoc, I realized, by interacting with several scientists, that the technical knowledge we acquire during our scientific education is not necessarily enough for a successful academic career. A whole set of non-technical skills are in fact needed 'to make it' in academia (not to mention, in life in general). Obvious, perhaps, to a successful academic, but not so when you just begin your PhD.

These soft skills include people and networking skills, communication skills, focus and perseverance, self-confidence, and persuasion. Some of these are innate abilities, and as such are more difficult to learn, but for all them, practice makes perfect. Since I became an editor, and became exposed to an even broader range of students and academics, I'm even more convinced that every student should recognise the importance of such skills and dedicate effort to developing them - they will help after a PhD, in any future job. I aim to provide here a few tips on how to hone these skills in an academic setting. If you are a seasoned researcher, what I am going to say is probably going to be familiar to you. But these are tips that I wish someone had shared with me back when I was a student.

\section{Talking about it}

When I travel to conferences and talk to researchers, I am always surprised to find that there are still some who do not appreciate the importance of effective communication, be it with their peers or the general public. You might achieve some amazing results, but if you are unable to describe them and share their significance with others, they are unlikely to leave a mark. Besides the necessary knowledge of a common language (which now is English), a lot of practice can help in writing clear, effective papers. Don't shy away from writing your own papers, and, in fact, be proactive and nominate yourself to your supervisor and collaborators as the person to draft the manuscript.

Read a lot. Identify what elements you liked of a well-written paper, then try to use the same narrative devices. Similarly, when you attend a talk that you find clear and inspiring, note down what struck you: the slides' style, the voice and body language of the speaker. At the first opportunity you have, try adopting those characteristics into your own presentations. The same can be said for posters. Practice explaining your research to your friends - can they actually understand what you do?

\section{People, people, people}

The single most important resource of any project is people. Getting the right people on board can make the difference between success and failure. But people are busy. They need a good reason to dedicate their time to you, so first of all you need to grab any opportunity you have to interact with your peers, particularly potential collaborators. When at conferences, so few students approach more senior scientists to discuss their work. I know that this can be daunting; students think 'he/she is not going to talk to a student', but that's the wrong attitude, as even the briefest conversation can be fruitful. Second, you want to leave a new acquaintance with a good, lasting impression of yourself by being polite and confident. Remember, also, that in any healthy scientific debate there is room for confrontation, but always with respect.

\section{Elevator pitch}

Can you explain the essence of your project and its implications in 60 seconds? If not, then think about it and rehearse until you can. For one, if you can't, it is questionable how much you 'own' your project. Have you understood the key elements, is the bigger picture clear in your mind? Second, treat meeting people at conferences like speed dating: you get their undivided attention for no more than a few minutes. Nobody wants to hear about other people's project for the whole duration of the lunch break. Finally, you should be confident in 'pitching' to your peers, as well as to non-scientists. This means you have to use a different approach depending on your audience.

\section{If you survived a PhD, there's little that can stop you.}

\section{Don't give up}

It doesn't matter how fast you run the first mile, if you can't run the whole course you are never going to finish the race. That is, perseverance and focus are key. If your gut (or your supervisor, whichever is the strongest voice) tells you that your project is going to work out, stick with it. Ups and downs are part of every $\mathrm{PhD}$ project and, regardless of whether your project turns out to be the flagship of the whole lab or not, you will learn that tasks that seem insurmountable at first can be tackled by breaking them down into manageable pieces. Once you've completed your $\mathrm{PhD}$, you will find that very few tasks will be really daunting - if you survived a $\mathrm{PhD}$, there's little that can stop you.

I might be naive, but I think that ultimately to succeed in academia it is important not to lose focus of the main reason why (most) people embark on a $\mathrm{PhD}$ : the drive to gain new knowledge about the world. When experiments don't work, it is easy to mentally drift away. When that happens, just stop for a moment and remind yourself of why you are passionate about science. It won't fix your experiments, but it will make you go back to the lab with renewed enthusiasm.

\section{ELISA DE RANIERI was at Nature}

Nanotechnology, and has recently moved to Nature Energy as a Senior Editor. e-mail: e.deranieri@nature.com 